RESEARCH REPORT

\title{
Relation between trends in late middle age mortality and trends in old age mortality-is there evidence for mortality selection?
}

\author{
F Janssen, A Peeters, J P Mackenbach, A E Kunst, for NEDCOM*
}

J Epidemiol Community Health 2005;59:775-781. doi: 10.1136/jech.2004.028407

See end of article for
authors' affiliations
$\ldots \ldots \ldots \ldots \ldots \ldots . . . . . . . .$.
Correspondence to:
Ms F Janssen, Department
of Public Health, Erasmus
MC, University Medical
Centre, Rotterdam, PO Box
1738,3000 DR
Rotterdam, Netherlands;
f.janssen@erasmusmc.nl
Accepted for publication
1 March 2005 ther mortality selection was a dominant factor in determining trends in old age Study objective: To test whether mortality selection was a dominant factor in determining trends in old age
mortality, by empirically studying the existence of a negative correlation between trends in late middle age mortality and trends in old age mortality among the same cohorts.

Design and methods: A cohort approach was applied to period data on total and cause specific mortality for Denmark, England and Wales, Finland, France, the Netherlands, Norway, and Sweden, in 19501999. The study described and correlated mortality trends for five year centralised cohorts from 1895 to 1910 at ages 55-69, with the trends for the same cohorts at ages 80-89. The research distinguished between circulatory diseases, cancers, and diseases specifically related to old age.

Main results: All cause mortality changes at ages 80-89 were strongly positively correlated with all cause mortality changes at ages 55-69, especially among men, and in all countries. Virtually the same correlations were seen between all cause mortality changes at ages 80-89 and changes in circulatory disease mortality at ages 55-69. Trends in mortality at ages 80-89 from infectious diseases, pneumonia, diabetes mellitus, symptoms, or external causes showed no clear negative correlations with all cause mortality trends at ages 55-69.

Conclusions: The consistently positive correlations seen in this study suggest that trends in old age mortality in north western Europe in the late 20th century were determined predominantly by the prolonged effects of exposures carried throughout life, and not by mortality selection.
$\mathrm{T}$ he aging of populations has important consequences for future demands of health care services and old age benefit systems. The degree of aging of populations is strongly influenced by future patterns of old age mortality. ${ }^{12}$ Therefore, projections of future mortality trends are highly important for public health. To make informed projections of future mortality trends it is important to accurately describe past trends in old age mortality and to analyse its determinants.

Past trends in old age mortality have been studied in many countries. Among low mortality countries, a general decline in mortality among those aged 80 and over since the 1950s has been found. ${ }^{3-6}$ However, when this period of mortality decline is examined more closely, important cross national differences in the pace of decline in old age mortality appear. From the 1980s onwards, mortality decline stagnated in Denmark, Netherlands, and among Norwegian men, while in other countries the mortality decline continued. ${ }^{7-9}$

The mechanisms behind these trends are still largely unknown. Next to effects of lifestyle or events occurring in late life itself, studies have focused on the effects of events or life style earlier in life, in accordance with the life course perspective. One mechanism mentioned in literature as a possible determinant of old age mortality trends, and one that is related to the life course perspective, is mortality selection. ${ }^{1} 7^{10} 11$

Mortality selection indicates that when mortality at younger ages is high, it tends to affect the frail people first, leaving a more selected and more robust population that survive up to high ages. ${ }^{12}$ With decreasing mortality at younger ages, the increasing proportion of the elderly population might be expected to be less healthy when compared with their more selected predecessors, ${ }^{1}$ and subsequently could experience comparatively higher morbidity and mortality at older ages.

Mortality selection effects have been posited in studies that use mathematical models to study cohort mortality, ${ }^{12-18}$ for example to explain the deceleration of the age pattern of mortality at older ages (for example, Horiuchi and Wilmoth ${ }^{16}$ ), or the black-white mortality crossover (for example, Manton and Stallard ${ }^{12}$ ). In addition, there is a long history of empirical cohort analyses of mortality. These studies focused mainly on the association between debilitating events or mortality in early life and mortality in adult ages. ${ }^{19-25}$ They showed predominantly positive associations, indicating no mortality selection. However, one study reported negative associations, ${ }^{26}$ and another reported no associations. ${ }^{27}$ Three other empirical studies, focusing more explicitly on old age mortality, did not find any empirical evidence for mortality selection. ${ }^{28-30}$

Thus, the evidence on mortality selection effects is rather mixed. Moreover, as most of these studies studied the mortality experience of single cohorts, little is known on the role of mortality selection in long term mortality trends. Furthermore, because previous studies often focused on the effects of mortality at very early ages on adult mortality, the effects of adult mortality on old age mortality are largely unknown.

The objective of this paper is to empirically study whether, and in what way, trends in late middle age mortality are correlated with old age mortality trends among the same cohorts. We hypothesise that mortality selection is a driving

* The Netherlands Epidemiology and Demography Compression of Morbidity research group, which also includes J J Barendregt, L Bonneux, C de Laet, W J Nusselder, O Franco Duran, A Al Mamun, and $\mathrm{F} J$ Willekens. 


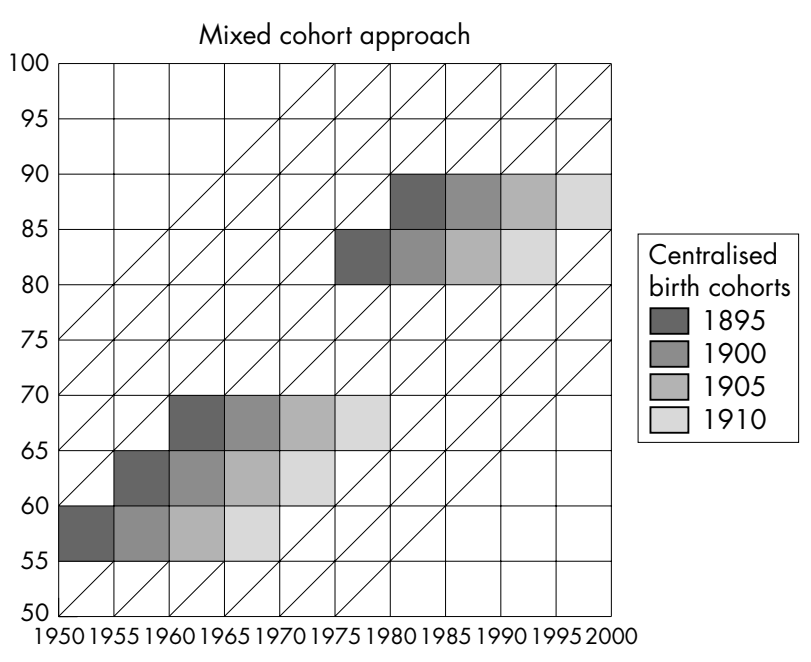

Figure 1 The mixed cohort approach applied to period data from 1950 to 1999 , for the ages 50 to 100 .

factor in old age mortality trends in seven north western European countries from 1950 to 1999. Consequently, we expect inverse correlations.

To test this hypothesis, we use data on all cause mortality and mortality data for causes of death that are especially susceptible to mortality selection-that is, circulatory diseases at late middle age and diseases specifically related to old age. Mortality declines in circulatory diseases (predominantly ischaemic heart disease) have been shown to lead to increased prevalence of chronic heart diseases at older ages, ${ }^{31}$ with subsequently higher mortality risks of related diseases. ${ }^{32}$ With respect to diseases specifically related to old age, recent mortality increases were observed. ${ }^{9}$ These increases could possibly result from an increasing proportion of frailer people at higher ages, due to decreased selection, because of mortality declines at younger ages.

In this study, we assess whether trends in old age mortality (ages 80-89) among subsequent birth cohorts are inversely correlated with mortality trends at late middle age (ages 5569 ) for the same cohorts, and whether different correlations are seen for (a) trends in circulatory diseases mortality at late middle age, and (b) mortality trends from diseases specifically related to old age.

\section{METHODS}

For this analysis, data on all cause mortality, cause specific mortality, and population numbers, by five year age groups and sex, were obtained from national statistical offices and related institutes, for Denmark, England and Wales, Finland, France, the Netherlands, Norway, and Sweden, for the years 1950 to 1999.

In addition to all cause mortality, we included three main groups of causes of death in our analysis: all circulatory diseases, all cancers, and the remaining causes of death. Within all circulatory diseases we distinguished between ischaemic heart diseases and cerebrovascular diseases. Within the remaining causes of death, we focused on diseases specifically related to old age-that is, infectious diseases, pneumonia, diabetes mellitus, dementia, and symptoms. See Janssen et al for the three digit codes used for these causes of death in the different revisions of the International Classification of Diseases (ICD) from the World Health Organisation. ${ }^{33}$ For ischaemic heart diseases we included the numbers of deaths for code 422.1 under ICD-6/7.

The use of three digit codes can still generate mortality discontinuities because of ICD revisions or incidental coding changes, such as the ones in England and Wales between 1984 and 1992, and in Sweden after 1980. ${ }^{33}$ We identified and adjusted for these coding related mortality discontinuities in our analysis. Adjustment involved the recalculation of the number of cause specific deaths by means of sex and cause specific transition coefficients. These transition coefficients are the parameter estimates of variables associated with a coding change (for example, ICD-8toICD-9), and obtained through sex specific regression models. In these regression models, cause specific mortality was the dependent variable and age, year of death, and variables associated with a coding change were independent variables. To obtain the sex and cause specific transition coefficients to recalculate cause specific deaths for those aged 55-69 and those aged 80-89, the regression model was applied to cause specific mortality among those aged 60 and over, and those aged 80 and over, respectively. For those aged 55-69, recalculation was applied to ischaemic heart diseases in the Netherlands and Sweden, and cerebrovascular diseases in Finland. For those aged 8089, deaths from all selected causes, except all circulatory diseases and infectious diseases, were adjusted for coding changes.

Table 1 (A) All cause mortality levels and trends, men aged 55-69 and 80-89, centralised birth cohorts 1895-1910, by country

\begin{tabular}{|c|c|c|c|c|c|c|c|}
\hline \multirow[b]{2}{*}{ Country } & \multicolumn{4}{|c|}{ Mortality rate $(\times 10000)$ by centralised birth cohort } & \multicolumn{3}{|c|}{$\begin{array}{l}\text { Relative change in mortality rate between subsequent } \\
\text { centralised birth cohorts }(\%)\end{array}$} \\
\hline & 1895 & 1900 & 1905 & 1910 & $1895-1900$ & $1900-1905$ & $1905-1910$ \\
\hline \multicolumn{8}{|l|}{ Aged 55-69 } \\
\hline Denmark & 212.46 & 225.84 & 229.71 & 224.01 & 6.29 & 1.71 & -2.48 \\
\hline England and Wales & 298.60 & 297.38 & 285.20 & 267.64 & -0.41 & -4.10 & -6.16 \\
\hline Finland & 345.14 & 342.36 & 335.37 & 320.07 & -0.80 & -2.04 & -4.56 \\
\hline France & 279.41 & 282.70 & 270.58 & 250.08 & 1.18 & -4.29 & -7.58 \\
\hline Netherlands & 203.58 & 217.06 & 229.24 & 229.41 & 6.62 & 5.61 & 0.07 \\
\hline Norway & 192.22 & 207.20 & 208.91 & 204.28 & 7.79 & 0.82 & -2.21 \\
\hline \multicolumn{8}{|l|}{ Aged 80-89 } \\
\hline Denmark & 1508.78 & 1485.48 & 1497.17 & 1476.78 & -1.54 & 0.79 & -1.36 \\
\hline England and Wales & 1725.58 & 1622.06 & 1511.90 & 1427.60 & -6.00 & -6.79 & -5.58 \\
\hline Finland & 1670.92 & 1638.10 & 1582.05 & 1508.16 & -1.96 & -3.42 & -4.67 \\
\hline France & 1595.21 & 1498.76 & 1356.52 & 1258.63 & -6.05 & -9.49 & -7.22 \\
\hline Netherlands & 1497.12 & 1494.98 & 1520.32 & 1498.09 & -0.14 & 1.70 & -1.46 \\
\hline Norway & 1479.93 & 1473.07 & 1477.12 & 1446.20 & -0.46 & 0.28 & -2.09 \\
\hline Sweden & 1556.02 & 1506.78 & 1442.75 & 1375.34 & -3.16 & -4.25 & -4.67 \\
\hline
\end{tabular}


Table 1 (B) All cause mortality levels and trends, women aged 55-69 and 80-89, centralised birth cohorts 1895-1910, by country

\begin{tabular}{|c|c|c|c|c|c|c|c|}
\hline \multirow[b]{2}{*}{ Country } & \multicolumn{4}{|c|}{ Mortality rate $(\times 10000)$ by centralised birth cohort } & \multicolumn{3}{|c|}{$\begin{array}{l}\text { Relative change in mortality rate between subsequent } \\
\text { centralised birth cohorts (\%) }\end{array}$} \\
\hline & 1895 & 1900 & 1905 & 1910 & $1895-1900$ & $1900-1905$ & $1905-1910$ \\
\hline \multicolumn{8}{|l|}{ Aged $55-69$} \\
\hline Denmark & 143.52 & 134.82 & 124.80 & 118.72 & -6.06 & -7.43 & -4.88 \\
\hline England and Wales & 152.94 & 144.10 & 136.86 & 132.50 & -5.78 & -5.02 & -3.19 \\
\hline Finland & 175.06 & 166.49 & 146.57 & 128.21 & -4.90 & -11.96 & -12.53 \\
\hline France & 144.73 & 131.19 & 119.31 & 106.29 & -9.35 & -9.05 & -10.91 \\
\hline Netherlands & 129.23 & 118.69 & 111.83 & 102.14 & -8.16 & -5.78 & -8.67 \\
\hline Norway & 121.47 & 114.11 & 106.87 & 98.75 & -6.06 & -6.35 & -7.60 \\
\hline $\begin{array}{l}\text { Sweden } \\
\text { Aged } 80-89\end{array}$ & 134.22 & 120.12 & 109.01 & 100.25 & -10.50 & -9.25 & -8.03 \\
\hline Denmark & 1098.45 & 1064.71 & 1037.78 & 1003.58 & -3.07 & -2.53 & -3.30 \\
\hline England and Wales & 1218.97 & 1104.13 & 1010.94 & 981.43 & -9.42 & -8.44 & -2.92 \\
\hline Finland & 1263.72 & 1213.57 & 1183.91 & 1095.07 & -3.97 & -2.44 & -7.50 \\
\hline France & 1146.66 & 1039.61 & 919.98 & 837.24 & -9.34 & -11.51 & -8.99 \\
\hline Netherlands & 1076.92 & 1017.34 & 1003.29 & 982.93 & -5.53 & -1.38 & -2.03 \\
\hline Norway & 1119.08 & 1065.37 & 1033.13 & 982.27 & -4.80 & -3.03 & -4.92 \\
\hline Sweden & 1131.19 & 1059.75 & 982.29 & 931.49 & -6.32 & -7.31 & -5.17 \\
\hline
\end{tabular}

We aggregated the mortality and population data into five year periods, and calculated five year age specific mortality rates by dividing the mortality data by the mid-year population estimates. To these period data, we applied a "mixed cohort approach", by using as the unit of observation centralised birth cohorts. In this approach, the data are combined by five year period and five year age group, and centred around the cohort calculated by subtracting the age group from the period (see fig 1). We were able to study four different centralised birth cohorts (those born around 1895, 1900, 1905, and 1910) to fulfil our aim of correlating mortality among those aged 55-69, with mortality among those aged 80-89 using the available data (1950-1999).

Cohort mortality rates for ages 55-69 and ages 80-89 were obtained by taking for each separate centralised cohort the unweighted average of the age specific rates over the three or two five year age groups, respectively. Relative changes in these cohort mortality rates were calculated by relating the mortality rate of a given centralised cohort to the mortality rate of the preceding centralised cohort.

As a first exploration of the mortality selection mechanism, we correlated all cause mortality levels between those aged 55-69 and those aged 80-89. Our main analysis, however, consisted of the correlation of relative cohort mortality changes between the late middle aged and the elderly population. For all cause mortality, we correlated absolute cohort mortality changes as well. Whereas absolute mortality changes more accurately express the importance of the mortality changes at younger ages, and the effect that they can have on trends in mortality at older ages, relative mortality changes can be more readily compared between countries.

The correlations were calculated across the seven countries, two sexes, and (changes in the) four centralised cohorts. In addition, correlations were calculated separately for men and women, each (change in) centralised cohort, and each country. The correlations of the mortality levels were stratified by sex.

In an additional analysis, we correlated the relative changes in all cause mortality trends-that is, the deceleration or acceleration of mortality trends in both late middle age and old age. We did so to find out if mortality at late middle age and old age is not only related in terms of the direction of mortality changes (is an increase in the one associated with a decrease in the other?) but also in terms of the pace of the mortality change (is an acceleration of the one associated with a deceleration in the other?). This additional analysis was conducted as an attempt to explain the deceleration of old age mortality decline that was seen in Denmark, the Netherlands, and among Norwegian men. ${ }^{9}$

Table 2 Correlation of all cause mortality levels at ages 55-69 with all cause mortality levels at ages 80-89, for men and women born to the centralised birth cohorts 18951910 among seven European countries, stratified by sex

\begin{tabular}{lllllll}
\hline \multirow{2}{*}{ Stratified by: } & \multicolumn{7}{l}{ Correlation of mortality levels } \\
\cline { 2 - 7 } & Total & (N) & Men & (N) & Women & $(\mathbf{N})$ \\
\hline All & $0.90^{* *}$ & $(56)$ & $0.52^{* *}$ & $(28)$ & $0.83^{* *}$ & $(28)$ \\
Centralised birth cohort 1895 & $0.91^{* *}$ & $(14)$ & $0.88^{* *}$ & $(7)$ & $0.87^{*}$ & $(7)$ \\
Centralised birth cohort 1900 & $0.93^{* *}$ & $(14)$ & $0.85^{*}$ & $(7)$ & $0.89^{* *}$ & $(7)$ \\
Centralised birth cohort 1905 & $0.90^{* *}$ & $(14)$ & 0.40 & $(7)$ & 0.65 & $(7)$ \\
Centralised birth cohort 1910 & $0.90^{* *}$ & $(14)$ & 0.22 & $(7)$ & 0.52 & $(7)$ \\
Denmark & $0.99^{* *}$ & $(8)$ & $\dagger$ & $(4)$ & $\dagger$ & $(4)$ \\
England and Wales & $0.96^{* *}$ & $(8)$ & $\dagger$ & $(4)$ & $\dagger$ & $(4)$ \\
Finland & $0.99^{* *}$ & $(8)$ & $\dagger$ & $(4)$ & $\dagger$ & $(4)$ \\
France & $0.94^{* *}$ & $(8)$ & $\dagger$ & $(4)$ & $\dagger$ & $(4)$ \\
Netherlands & $0.99^{* *}$ & $(8)$ & $\dagger$ & $(4)$ & $\dagger$ & $(4)$ \\
Norway & $0.99^{* *}$ & $(8)$ & $\dagger$ & $(4)$ & $\dagger$ & $(4)$ \\
Sweden & $0.99^{* *}$ & $(8)$ & $\dagger$ & $(4)$ & $\dagger$ & $(4)$ \\
\hline
\end{tabular}

*Correlation is significant at the 0.05 level (two tailed); ${ }^{* *}$ correlation is significant at the 0.01 level (two tailed); too few observations. 


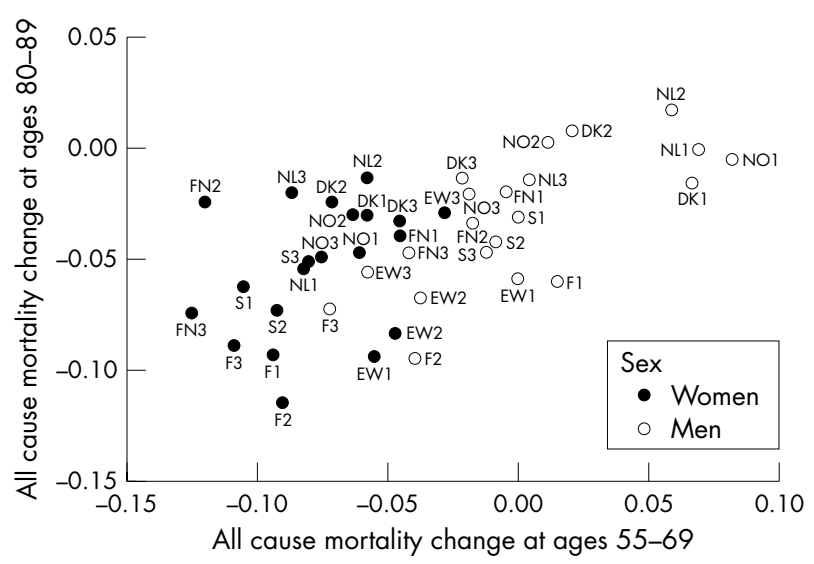

Figure 2 Scatter plot of the correlation of relative changes in all cause mortality at ages 55-69 and at ages 80-89, for men and women born to the centralised cohorts 1895-1910 among seven European countries. DK, Denmark; EW, England and Wales; FN, Finland; F, France; NL, the Netherlands; NO, Norway; S, Sweden. 1, cohort change 1895-1900; 2, cohort change 1900-1905; 3, cohort change 1905-1910.

To check the robustness of our results, different age groups were used when correlating all cause mortality trends-that is, ages 70-79 instead of 55-69 and ages 80-94 instead of 80-89. For the latter analysis only three instead of four centralised cohorts could be analysed.

\section{RESULTS}

Among those aged 55-69, mortality levels were highest in Finland, England and Wales, and France (men), and lowest in Norway, Sweden, and the Netherlands (women) (table 1). Among those aged 80-89, Finland had by far the highest mortality level, and France the lowest level, especially among the more recent cohorts. Correlation between all cause mortality levels of those aged 55-69 and those aged 80-89, showed highly positive and significant correlations, among both men and women, although less so for the more recent cohorts (table 2).

All cause mortality generally declined over the five year centralised birth cohorts from 1895 to 1910 both among men and women aged 55-69 and among men and women aged 80-89 (table 1). The trends for men in Denmark, the Netherlands, and Norway were less favourable. Correlations between both relative and absolute changes in all cause mortality at ages 55-69 with those at ages 80-89 were significant and positive ( 0.61 and 0.58 , respectively) (table 3 , fig 2). Among men, the correlation coefficients were especially high (0.7). Among women, the correlations were lower $(0.3)$ and not statistically significant. The correlations were strongest for the Netherlands, Norway, and Sweden (men only).

Circulatory disease mortality among those aged 55-69 generally declined over subsequent centralised birth cohorts (data not shown). For men, this decline started only among later cohorts. For Dutch men, circulatory disease mortality increased. Relative changes in circulatory disease mortality at ages 55-69 correlated significantly and positively with all cause mortality changes at ages 80-89 (0.61) (table 4). For women, the positive correlation was not significant. Correlations of all cause mortality changes at ages 80-89 with trends in mortality from ischaemic heart diseases and cerebrovascular diseases at ages 55-69 were also significant and positive, but less strong (0.40 and 0.42 , respectively).

All cause mortality trends at ages 55-69 correlated significantly and positively with mortality trends in circulatory diseases and cancer at ages 80-89 (0.58 and 0.69, respectively) (table 5). The positive correlation for cancer mortality was seen for both men and women, whereas for circulatory diseases only for men. All cause mortality trends at ages 55-69 did not clearly correlate with mortality trends at ages 80-89 from diseases other than circulatory diseases and cancer, nor with diseases specifically related to old age, such as infectious diseases, pneumonia, diabetes mellitus, dementia, symptoms, and external causes of death. A significant positive correlation was found only for diabetes mellitus and symptoms (among women). While a few inverse correlations were seen, especially for pneumonia, these correlations were weak, inconsistent, and non-significant.

Acceleration or deceleration of mortality trends among those aged 80-89 was positively correlated with the pace of mortality change among those aged 55-69, although correlations were weak (0.27) and non-significant.

Trends in all cause mortality at ages 70-79 (instead of 5569 ) correlated significantly and highly positive with trends in all cause mortality at ages 80-89 (0.69). The correlation of all cause mortality changes at ages 55-69 with those at ages 8094 (instead of 80-89) was significant and positive (0.59) as well.

Table 3 Correlation of relative and absolute cohort changes in all cause mortality at ages 55-69 with relative and absolute cohort changes in all cause mortality at ages $80-89$, for men and women born to the centralised birth cohorts 1895-1910 among seven European countries

\begin{tabular}{lclll}
\hline & & \multicolumn{2}{l}{ Correlation of mortality changes } \\
\cline { 4 - 5 } Stratified by: & N & Relative & Absolute \\
\hline All & 42 & $0.61^{* *}$ & $0.58^{* *}$ \\
Men & 21 & $0.71^{* *}$ & $0.70^{* *}$ \\
Women & 21 & 0.33 & 0.32 \\
Cohort changet 1895 to 1900 & 14 & $0.74^{* *}$ & $0.61^{*}$ \\
Cohort changet 1900 to 1905 & 14 & $0.56^{*}$ & $0.64^{*}$ \\
Cohort changet 1905 to 1910 & 14 & $0.74^{* *}$ & $0.82^{* *}$ \\
Denmark & 6 & 0.63 & 0.44 \\
England and Wales & 6 & 0.41 & 0.20 \\
Finland & 6 & 0.52 & 0.37 \\
France & 6 & 0.64 & 0.08 \\
Netherlands & 6 & 0.78 & 0.79 \\
Norway & 6 & $0.84^{*}$ & 0.76 \\
Sweden & 6 & $0.88^{*}$ & 0.54 \\
\hline & & &
\end{tabular}


Table 4 Correlation of relative changes in circulatory disease mortality at ages 55-69 with relative changes in all cause mortality at ages $80-89$, for men and women born to the centralised birth cohorts 1895-1910 among seven European countries

\begin{tabular}{|c|c|c|c|c|c|c|}
\hline & All & Men & Women & $\begin{array}{l}\text { Cohort } \\
\text { change† } \\
1895- \\
1900\end{array}$ & $\begin{array}{l}\text { Cohort } \\
\text { changet } \\
1900- \\
1905\end{array}$ & $\begin{array}{l}\text { Cohort } \\
\text { changet } \\
1905- \\
1910\end{array}$ \\
\hline Causes of death at ages 55-69 & $\mathrm{N}=42$ & $\mathrm{~N}=21$ & $\mathrm{~N}=21$ & $N=14$ & $N=14$ & $\mathrm{~N}=14$ \\
\hline All circulatory diseases & $0.61^{* *}$ & $0.70^{* *}$ & 0.40 & $0.77^{* *}$ & $0.56^{*}$ & $0.60^{*}$ \\
\hline Ischaemic heart diseases & $0.40^{* *}$ & 0.40 & 0.12 & $0.84^{* *}$ & 0.47 & 0.39 \\
\hline Cerebrovascular diseases & $0.42^{* *}$ & 0.41 & 0.09 & 0.39 & 0.50 & 0.47 \\
\hline
\end{tabular}

\section{DISCUSSION}

In this paper, we explored the relation between mortality trends in late middle age (55-69) and mortality trends in old age (80-89) for male and female cohorts born around 1895 , 1900, 1905, and 1910 in seven European low mortality countries. All cause mortality changes at ages $80-89$ are strongly positively correlated with all cause mortality changes at ages 55-69, especially among men, and in all countries. Virtually the same correlations were seen between all cause mortality changes at ages $80-89$ and changes in circulatory disease mortality at ages 55-69. Mortality trends at ages 8089 from diseases specifically related to old age-that is, infectious diseases, pneumonia, diabetes mellitus, symptoms, and external causes, showed no clear negative correlations with all cause mortality trends at ages 55-69.

This evidence suggests that mortality selection has not been a driving factor behind old age mortality trends in the countries under study. Our results were found robust against the selection of different age groups (70-79 instead of 55-69 and 80-94 instead of 80-89). Furthermore, we found no indications that the recent deceleration of the mortality decline among the elderly population in Denmark, the Netherlands, and Norway was related to accelerated declines in mortality at earlier ages of the same cohorts.

This study is unique in its attempt to link, in a cohort-wise manner, trends in middle age mortality with trends in old age mortality. Perhaps closest to our study is a study by Manton on the effects of increases in life expectancy at advanced ages on mortality from conditions associated with a debilitation at those ages. He also found no evidence for decreased selectivity. ${ }^{29}$ Persons who survive up to age 85 were on average healthier than their predecessors, in contrast with what would be expected according to the mortality selection theory when mortality is improving.

\section{Evaluation of data and methods}

The mortality and population data used in this study stem from countries considered to have good or excellent population and vital registries. ${ }^{45}$ Reported survivorship counts are highly accurate. ${ }^{54}$ Comparison of our mortality data with the mortality data among those aged 80 and over from the Kannisto-Thatcher database ${ }^{5}$-in which the data were checked for age heaping and were subjected to a number of checks for plausibility-showed only small discrepancies.

In our analysis, we applied a mixed cohort approach—that is, a cohort approach applied to period data. A pure cohort approach was difficult to conduct with the available data, and would have led to the inclusion of only three subsequent five year cohorts, which we considered too few for correlation analyses. A disadvantage of the mixed cohort approach is that it cannot clearly separate subsequent cohorts. Consequently, the identified cohorts overlap, which could lead to an underestimation of mortality trends and possibly to a dilution of the strength of the correlations between trend

Table 5 Correlation of relative changes in all cause mortality at ages 55-69 with relative mortality changes in specific causes of death at ages $80-89$, for men and women born to the centralised birth cohorts 1895-1910 among seven European countries

\begin{tabular}{|c|c|c|c|c|c|c|}
\hline \multirow[b]{2}{*}{ Causes of death at ages $80-89$} & \multirow{2}{*}{$\begin{array}{l}\text { All } \\
\mathrm{N}=42\end{array}$} & \multirow{2}{*}{$\frac{\text { Men }}{\mathrm{N}=21}$} & \multirow{2}{*}{$\begin{array}{l}\text { Women } \\
\mathrm{N}=21\end{array}$} & \multirow{2}{*}{ 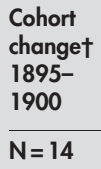 } & \multirow{2}{*}{$\begin{array}{l}\begin{array}{l}\text { Cohort } \\
\text { changet } \\
1900-\end{array} \\
1905 \\
N=14\end{array}$} & \multirow{2}{*}{ 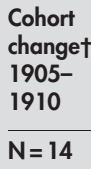 } \\
\hline & & & & & & \\
\hline All circulatory diseases & $0.58^{* *}$ & $0.66^{* *}$ & 0.14 & $0.63^{*}$ & $0.54^{*}$ & 0.51 \\
\hline All cancers & $0.69^{* *}$ & $0.54^{*}$ & $0.49^{*}$ & $0.64^{*}$ & $0.79^{* *}$ & 0.50 \\
\hline All other causes & 0.17 & 0.40 & 0.19 & 0.26 & 0.14 & 0.42 \\
\hline \multicolumn{7}{|c|}{ Diseases specifically related to old age within "all other causes": } \\
\hline Infectious diseases & 0.01 & 0.15 & 0.26 & -0.15 & 0.14 & 0.43 \\
\hline Pneumonia & -0.03 & -0.14 & -0.23 & -0.15 & 0.14 & 0.25 \\
\hline Diabetes mellitus & $0.44^{\star *}$ & 0.11 & 0.42 & 0.44 & 0.33 & $0.55^{*}$ \\
\hline Dementia & 0.18 & 0.25 & 0.21 & -0.23 & 0.37 & 0.44 \\
\hline $\begin{array}{l}\text { All symptoms and ill defined } \\
\text { conditions }\end{array}$ & 0.07 & -0.12 & $0.62^{* *}$ & -0.25 & 0.13 & 0.35 \\
\hline All other diseases $\ddagger$ & 0.22 & $0.67^{* *}$ & 0.13 & 0.45 & -0.03 & 0.17 \\
\hline All external causes of death & $0.39^{*}$ & 0.33 & -0.09 & 0.42 & 0.36 & 0.18 \\
\hline
\end{tabular}

†Relative change in mortality rates between the two subsequent centralised birth cohorts. $¥$ This refers to all diseases not included in this table - that is, all cause mortality minus all circulatory diseases, all cancers, infectious diseases, pneumonia, diabetes mellitus, dementia, "all symptoms and ill defined conditions", and all external causes of death. * ${ }^{*}$ Correlation is significant at the 0.05 level (two tailed); ** correlation is significant at the 0.01 level (two tailed). 


\section{Key points}

- The evidence on mortality selection effects is rather mixed, and studied predominantly by relating mortality at very early ages with adult mortality among single cohorts. Consequently, little is known on mortality selection effects of mortality trends at adult ages on old age mortality trends.

- In all countries under study, trends in mortality at late middle age correlate positively with trends in old age mortality of the same birth cohorts.

- Positive correlations are also seen with trends in mortality from cardiovascular diseases at late middle age. Weak, but not inverse correlations are seen with trends in mortality from diseases specifically related to old age.

- The observed positive correlations point to effects of early life circumstances carried throughout life and prolonged exposure to, or longlasting effect of, risk factors emerging in adult life. Effects of mortality selection seem to be of lesser importance in determining old age mortality trends.

- Our results do not support the concern that strong declines in middle age mortality will lead to an increase in old age mortality for the same cohorts.

estimates. However, some dilution of effect could not explain the observed positive instead of inverse relation between mortality trends at late middle age and old age.

We made an extraordinary effort to deal with ICD and other coding related changes that can affect cause specific mortality trends, and that are often neglected in other studies. Even though some residual effects of coding problems could not be excluded, we expect that these problems did not affect the results to any substantial extent. ${ }^{8} 933$

We do not expect that the potentially inferior quality of cause of death coding among the very elderly as compared with the late middle age would substantially affect our results. The quality of coding can only bias the correlation of trends if clear changes in the quality of coding over time occurred, which is unlikely.

\section{Explanations of the absence of hypothesised inverse correlations}

One possible explanation of the lack of negative correlations is that our study lacked potential to empirically observe an effect of mortality selection, because of comparatively little variation in mortality at younger ages between subsequent cohorts. Larger variations were, however, seen between the selected countries. Moreover, life table calculations for the Netherlands in 1950 showed that the mortality declines among those aged 55-69 within most individual countries were large enough to influence mortality trends among those aged 80-89. Considering the extreme situation in which all people saved from dying in the younger group will eventually die in the older group, a 10\% mortality reduction among those aged 55-69 would lead to a mortality increase at age $80-89$ years of $14 \%$ among men, and of $11 \%$ among women.

The lack of empirical support to the mortality selection hypothesis could also possibly be explained by not considering the greatest advances in medical care and resulting mortality declines since the 1970s among those aged 55-69. ${ }^{35}$ Improvements in medical care and new treatments lead to higher prevalences in chronic disease for those who survive, ${ }^{29}$ which could result in higher mortality at higher ages from these diseases. Although we cannot exclude that more recent declines in mortality at ages 55-69 might influence trends in old age mortality for more recent cohorts and future periods differently, our finding that positive correlations were also seen among the more recent cohorts studied, which were also characterised by important declines in mortality at middle age, casts doubt about the potential of mortality selection to determine future old age mortality trends.

\section{Explanations of the positive correlations observed}

The consistently positive correlations seen in our analysis suggest the existence of parallel trends in late middle age mortality and old age mortality. This points to common mechanisms that develop in a cohort-wise fashion.

It has frequently been mentioned in literature that risks established early in life influence health conditions at adult ages. Examples of relevant exposures include nutrition in utero, exposure to infectious diseases, and/or socioeconomic circumstances in infancy or childhood. ${ }^{19-23} 36$ Less clear is whether the effects of early life events last until old age. ${ }^{17} 2627$ Our results could indicate that effects of early life events or conditions, that have been shown to influence mortality risk at late middle age, have the potential to exert their influence until old age.

Prolonged exposure to, or longlasting effects of, risks emerging during adult age might be another factor contributing to the observed positive correlations. Additional analyses showed that changes in circulatory disease mortality at ages 55-69 correlated most strongly with changes in mortality at ages 80-89 from circulatory diseases $(0.61)$ and cancers $(0.54)$, and hardly with old age mortality changes in remaining causes of death $(0.15)$ and infectious diseases $(-0.10)$. This indeed suggests that risk factors for circulatory diseases, like physical activity, hypertension, diet, smoking, and utilisation of medical care ${ }^{37-39}$ emerging during adult age, are common determinants of mortality at both adult and old age among the same cohorts. With respect to smoking among men, changes in all cause mortality at ages 55-69 were indeed strongly correlated to changes in mortality from lung cancer at ages 80-89 (0.71).

\section{Implications}

The consistently positive correlations between mortality changes at late middle age and mortality changes among the elderly population suggest that old age mortality trends in north western Europe in the late 20th century are determined predominantly by the effects of early life circumstances carried throughout life and prolonged exposure to, or longlasting effects of, risk factors emerging in adult life. Mortality selection has no discernible effect on secular trends in mortality. Our results, thus, do not support the concern that strong declines in middle age mortality will ultimately lead to increases in old age mortality for the same cohorts. In fact, the positive associations seen in our study suggest that recent trends in all cause mortality among the middle aged may be used to inform projections of future trends in all cause mortality among the elderly population.

\section{ACKNOWLEDGEMENTS}

We are grateful to Jacques Vallin (INED, France), Martine Bovet (INSERM, France), Hilkka Ahonen (Statfin, Finland), Annika Edberg (National Board of Health and Welfare, Sweden), Örjan Hemström (Sweden), Allan Baker and Glenn Meredith (ONS, England and Wales), Knud Juel (National Institute of Public Health, Denmark) and Jens-Kristian Borgan (Statistics Norway) for providing cause specific mortality and population data. 


\section{Authors' affiliations}

F Janssen, A Peeters, J P Mackenbach, A E Kunst, Department of Public Health, Erasmus MC, University Medical Centre Rotterdam, Rotterdam, Netherlands

A Peeters, Department of Epidemiology and Preventive Medicine, Monash University, Central and Eastern Clinical School, Alfred Hospital Melbourne, Victoria, Australia

Funding: this paper is part of a project financed by the sector of Medical Sciences of the Organisation for Scientific Research, the Netherlands (ZonMw).

Conflicts of interest: none.

\section{REFERENCES}

1 Grundy E. Demography and gerontology: mortality trends among the oldest old. Ageing and Society 1997; 17:713-25.

2 Preston SH, Himes C, Eggers M. Demographic conditions responsible for population aging. Demography 1989;26:691-704.

3 Thatcher AR. Trends in numbers and mortality at high ages in England and Wales. Population Studies 1992;46:411-26.

4 Kannisto V, Lauritsen J, Thatcher AR, et al. Reductions in mortality at advanced ages: several decades of evidence from 27 countries. Population and Development Review 1994;20:793-810.

5 Kannisto V. Development of oldest-old mortality, 1950-1990: evidence from 28 developed countries. Odense, Denmark: Odense University Press, 1994.

6 Vaupel JW. The average French baby may live 95 to 100 years. In: Robine J-M, Vaupel J, Jeune B, et al, eds. Longevity: to the limits and beyond. Berlin: Springer-Verlag, 1997.

7 Nusselder WJ, Mackenbach JP. Lack of improvement of life expectancy at advanced ages in the Netherlands. Int J Epidemiol 2000;29:140-8.

8 Janssen F, Nusselder WJ, Looman CWN, et al. Stagnation in mortality decline among elders in the Netherlands. Gerontologist 2003;43:722-34.

9 Janssen F, Mackenbach JP, Kunst AE. Trends in old-age mortality in seven European countries, 1950-1999. J Clin Epidemiol 2004;57:203-16.

10 Caselli G, Lopez ADE. Health and mortality among elderly populations. Oxford: Clarendon Press, 1996.

11 Nusselder WJ, Mackenbach JP. Rectangularization of the survival curve in the Netherlands: an analysis of underlying causes of death. J Gerontol B Psychol Sci Soc Sci 1997;52:S145-54.

12 Manton KG, Stallard E. Methods for evaluating the heterogeneity of aging processes in human populations using vital statistics data: explaining the black/white mortality crossover by a model of mortality selection. Hum Biol 1981;53:47-67.

13 Vaupel JW, Manton KG, Stallard E. The impact of heterogeneity in individual frailty on the dynamics of mortality. Demography 1979;16:439-54.

14 Manton KG, Stallard E, Vaupel JW. Methods for comparing the mortality experience of heterogeneous populations. Demography 1981;18:389-410.

15 Vaupel JW, Yashin AY, Manton KG. Debilitation's aftermath: stochastic process models of mortality. Mathematical Population Studies 1988;1:21-49.

16 Horiuchi S, Wilmoth JR. Deceleration in the age pattern of mortality at olde ages. Demography 1998;35:391-412.

17 Barbi E, Caselli G. Selection effects on regional differences in survivorship in Italy. Genus 2003; LIX:37-61

18 Foster A. Are cohort mortality rates autocorrelated? Demography 1991;28:619-37.
19 Kermack WO, McKendrick AG, McKinlay PL. Death-rates in Great Britain and Sweden. Some general regularities and their significance. Lancet 1934;226:698-703.

20 Livi Bacci $M$. Alcune considerazioni sulle tendenza della mortalità senile e sull'eventuale influenza selettiva della mortalità infantile. Rivista Italiana di Economia 1962;18:60-73.

21 Forsdahl A. Are poor living conditions in childhood and adolescence an important risk factor for arteriosclerotic heart disease? Br J Prev Soc Med 1977:31:91-5.

22 Preston SH, Van de Walle E. Urban French mortality in the nineteenth century. Population Studies 1978;32:275-97.

23 Horiuchi S. The long-term impact of war on mortality: old-age mortality of the first world war survivors in the Federal Republic of Germany. Population Bulletin of the United Nations 1983;15:80-92.

24 Bengtsson T, Lindstrom M. Airborne infectious diseases during infancy and mortality in later life in southern Sweden, 1766-1894. Int J Epidemiol 2003;32:286-94

25 Finch CE, Crimmins EM. Inflammatory exposure and historical changes in human life-spans. Science 2004;305:1736-9.

26 Caselli G, Capocaccia R. Age, period, cohort and early mortality: an analysis of adult mortality in Italy. Population Studies 1989:43:133-53.

27 Kannisto V, Christensen K, Vaupel JW. No increased mortality in later life for cohorts born during famine. Am J Epidemiol 1997; 145:987-94.

28 Coale AJ, Kisker EE. Mortality crossovers: reality or bad data? Population Studies 1986;40:389-401

29 Manton KG. Cause specific mortality patterns among the oldest old: multiple cause of death trends 1968 to 1980. J Gerontol 1986;41:282-9.

30 Kannisto V. Frailty and survival. Genus 1991;47:101-18.

31 Bonneux L, Barendregt JJ, Meeter K, et al. Estimating clinical morbidity due to ischemic heart disease and congestive heart failure: the future rise of heart failure. Am J Public Health 1994;84:20-8.

32 Bonneux L, Looman CW, Barendregt JJ, et al. Regression analysis of recent changes in cardiovascular morbidity and mortality in the Netherlands. BMJ 1997;314:789-92.

33 Janssen $F$, Kunst $A E$. ICD coding changes and discontinuities in trends in cause-specific mortality in six European countries, 1950-99. Bull World Health Organ 2004;82:904-13.

34 Condran AG, Himes CL, Preston SH. Old-age mortality patterns in lowmortality countries: An evaluation of population and death data at advanced ages, 1950 to the present. Population Bulletin of the United Nations 1991;30:23-60.

35 Mackenbach JP, Looman CW, Kunst AE, et al. Post-1950 mortality trends and medical care: gains in life expectancy due to declines in mortality from conditions amenable to medical intervention in the Netherlands. Soc Sci Med 1988;27:889-94.

36 Barker DJ. Fetal and infant origins of adult disease. London: BMJ Books, 1992.

37 Sarti C, Rastenyte D, Cepaitis Z, et al. International trends in mortality from stroke, 1968 to 1994. Stroke 2000;31:1588-601.

38 Kuulasmaa K, Tunstall-Pedoe H, Dobson A, et al. Estimation of contribution of changes in classic risk factors to trends in coronary-event rates across the WHO MONICA Project populations. Lancet 2000;355:675-87.

39 Cooper R, Cutler J, Desvigne-Nickens P, et al. Trends and disparities in coronary heart disease, stroke, and other cardiovascular diseases in the United States: findings of the national conference on cardiovascular disease prevention. Circulation 2000;102:3137-47. 